\title{
Pancake-like gadolinium enhancement in the spinal cord: an image pattern that suggests spondylotic myelopathy
}

Realce pelo gadolínio "em panqueca" na medula espinhal: um padrão de imagem sugestivo de mielopatia espondilótica

Gabriela Cezana Contarato1, Marcos Rosa Júnior²

A 55-year-old man without comorbidities presented with progressive paresthesia and weakness affecting the limbs. Cervical magnetic resonance imaging (MRI) demonstrated prominent spondylosis and myelopathy with pancake-like gadolinium enhancement (Figures 1 and 2).

The pancake-like sign is related to a focal disruption of the blood-brain barrier and defined by a circumferential enhancement sparing spinal cord gray matter on axial images, located beneath the site of maximum stenosis, with a transverse band appearance on sagittal images, extending less than one vertebral segment. The recognition of these radiological findings contribute to the avoidance of unnecessary interventions ${ }^{1,2,3}$.
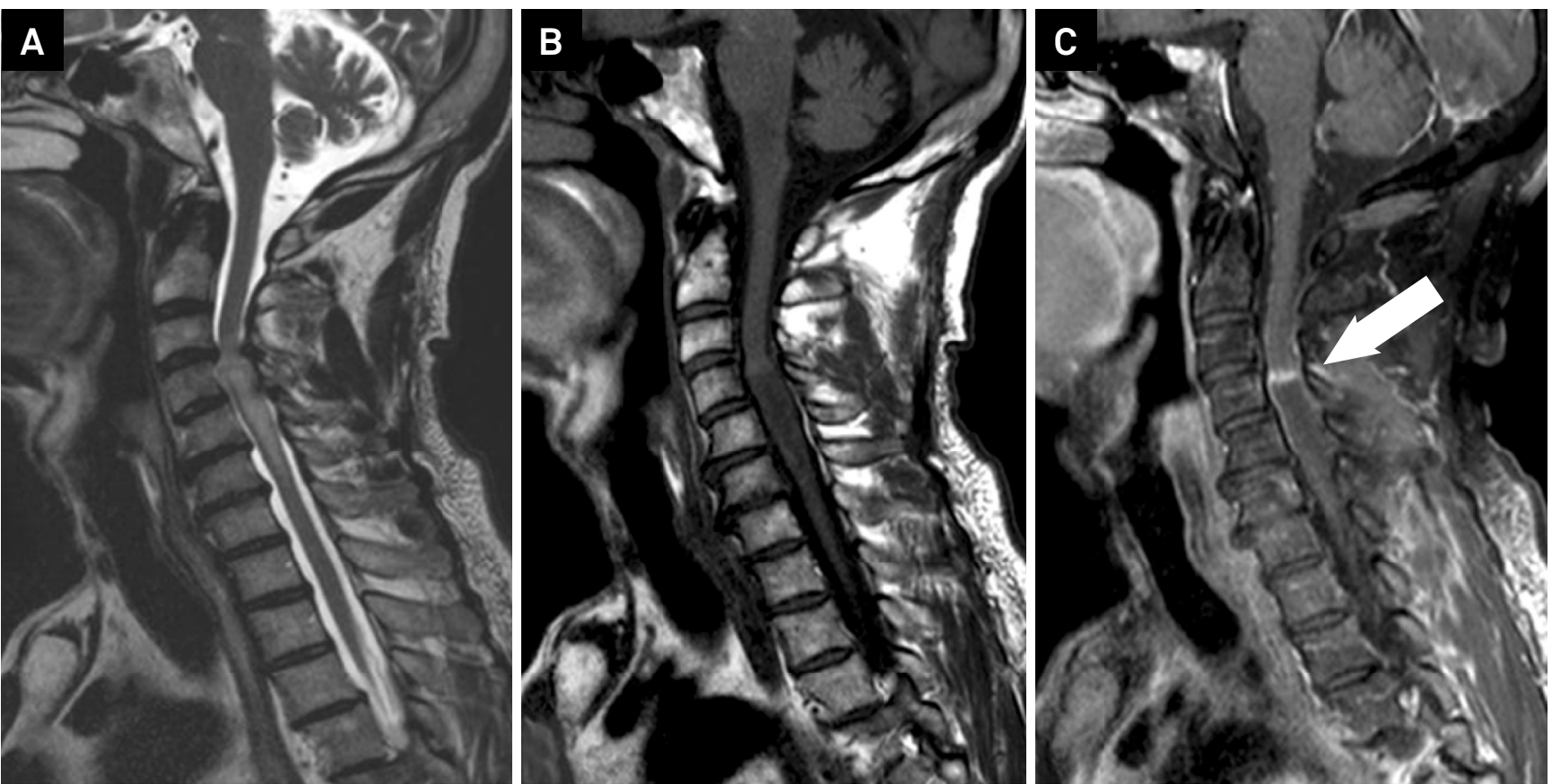

Figure 1. Sagittal MRI reveals prominent cervical spondylosis associated with a fusiform longitudinally-extensive hyperintensity on T2-weighted image, below compression, due to spinal vasogenic edema (A), hypointensity on T1-weighted image (B), with a transverse pancake-like band of enhancement at the spinal cord just below the site of maximal stenosis (C3-C4) on T1-weighted post-gadolinium image (C).

${ }^{1}$ Universidade Federal do Espírito Santo, Vitória ES, Brasil;

${ }^{2}$ Universidade Federal do Espírito Santo, Departamento de Neurorradiologia, Vitória ES, Brasil.

Correspondence: Marcos Rosa Júnior; Avenida Marechal Campos, 1468; Maruípe, 29043-900 Vitória ES, Brasil; E-mail: marcosrosajr@hotmail.com

Conflict of interest: There is no conflict of interest to declare.

Received 08 January 2018; Received in final form 03 February 2018; Accepted 06 February 2018. 

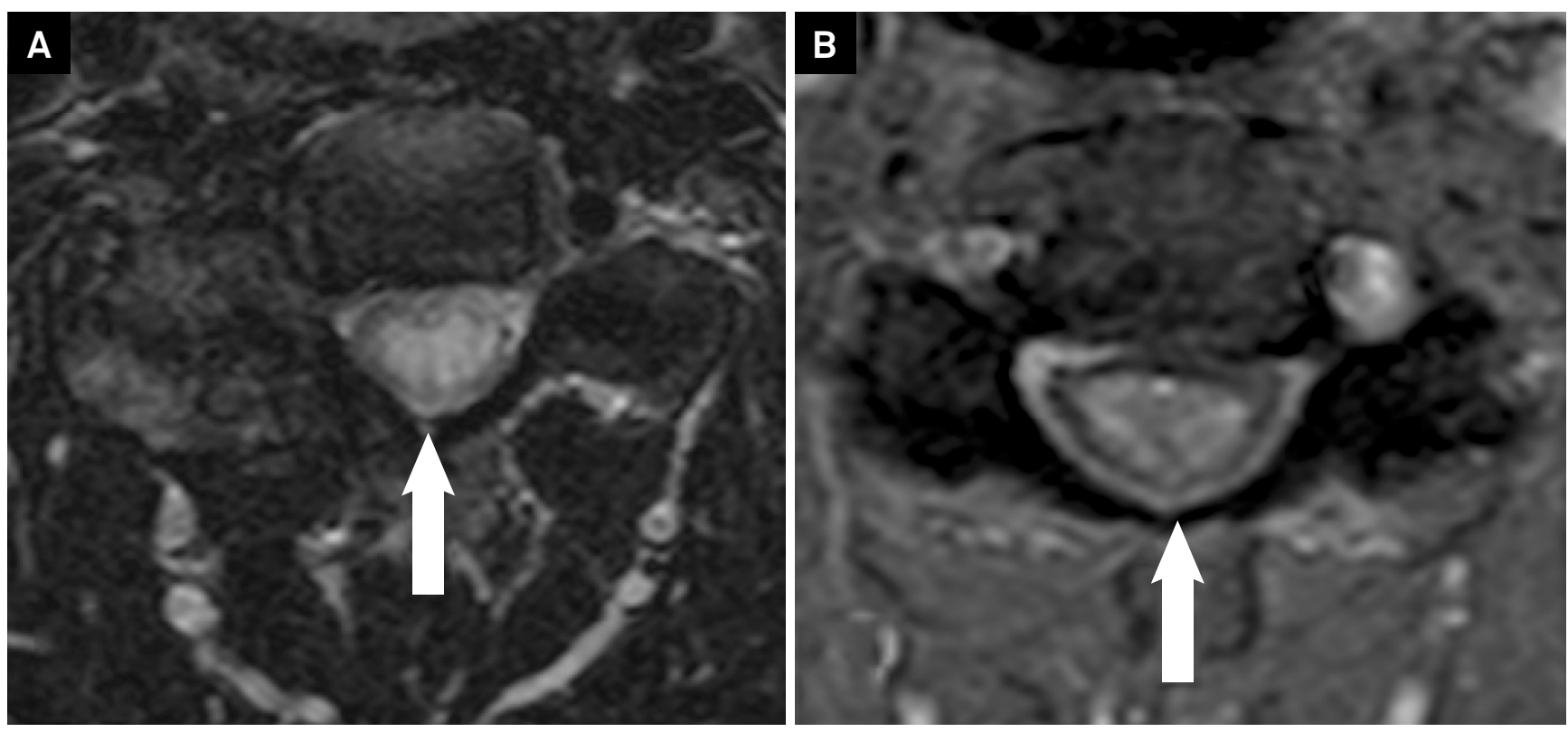

Figure 2. The pancake-like sign on axial T2-weighted image (A) and axial T1-weighted post-gadolinium (B), showing a circumferential enhancement sparing spinal cord gray matter (B).

\section{References}

1. Seidenwurm DJ. Myelopathy. Am J Neuroradiol. 2008;29(5):1032-4.

2. Flanagan EP, Krecke KN, Marsh RW, Giannini C, Keegan M, Weinshenker BG. Specific pattern of gadolinium enhancement in spondylotic myelopathy. Ann Neurol. 2014;76(1):54-65. https://doi.org/10.1002/ana.24184
3.

Flanagan EP, Marsh RW, Weinshenker BG. Teaching neuroimages: "pancake-like" gadolinium enhancement suggests compressive myelopathy due to spondylosis. Neurology. 2013;80(21):e229. https://doi.org/10.1212/WNL.0b013e318293e346 